\title{
Organ Transplantation in the Face of Donor Shortage - Ethical Implications with a Focus on Liver Allocation
}

\author{
Michael Lauerer Katharina Kaiser Eckhard Nagel \\ Institut für Medizinmanagement und Gesundheitswissenschaften, Universität Bayreuth, Bayreuth, Germany
}

\section{Keywords}

Organ allocation - Priority setting .

Transplantation medicine

\section{Summary}

Background: Transplantation medicine is associated with several ethical issues related to the lack of organs. Major questions concern the regulations for giving permission for organ removal, informing the public about organ donation, setting of organ allocation priorities, waiting list access, and strategies to counteract scarcity. Methods: This contribution is based on analyses of legal regulations, guidelines of self-regulatory bodies, administrative data, and literature from medical, normative, and empiric disciplines. It addresses the above-mentioned issues descriptively with a focus on Germany and liver transplantation. Results: The basic principle of beneficence justifies a shift from voluntariness towards an obligation to document one's decision regarding organ donation. Organ allocation is obviously tangent to fundamental values and concepts of justice. At that, there is no consistent agreement on whether to prioritize the sickest patient or to maximize the overall health benefit. Restrictions relating to waiting list access are the subject of controversies. The reasons for denial of access are largely related to high demands on the prospect of success. Strategies to counteract organ scarcity partly conflict with the respect for autonomy, non-maleficence, beneficence, or justice. Conclusion: We propose to focus on recent most promising strategies to counteract scarcity in the short-term: demanding a documented decision on organ donation and an orientation towards the Spanish model of organization. Concepts for waiting list access should constantly be reviewed considering all medical evidence and must not be based on moralism.
Moreover, we suggest to consider public preferences for organ allocation and strengthen the confidence in transplantation medicine.

(c) 2016 S. Karger GmbH, Freiburg

\section{Introduction}

Beneficially successful transplantation medicine is associated with several ethical issues (table 1) most of which relate to the lack of organs or are at least discussed against the background of donor shortage. Data from Eurotransplant quantify the gap between supply and demand [1]: In Germany, in 2014, 3,028 deceased donor transplants were opposed to 5,443 registration events on the waiting lists. 10,585 patients were registered on these lists at the end of 2014. In total, 892 registered patients died while they were waiting for an organ. More people died unfit for transplantation after being removed from the waiting list or without ever being listed. Major ethical questions in this context concern the regulations for giving permission for organ (and tissue) removal and informing the public about organ donation. Obviously, priority setting for the allocation of the scarce post-mortem donor organs is a crucial challenge. This applies even more in the light of conflicting allocation criteria. The regulation of waiting list access also raises ethical questions, particularly if not everyone who could profit from organ transplantation is entitled to be registered. Other ethical questions pertain to acceptable strategies to fill the gap between the supply and demand for donor organs. Figure 1 outlines the main points of this contribution. Brain death as a prerequisite for organ removal and alternative proposals are not the subject of this contribution as we believe that they should be discussed independently.

The summary is based on analyses of legal regulations (German Transplantation Act (Transplantationsgesetz (TPG)) and Basic

\section{KARGER}

(c) 2016 S. Karger GmbH, Freiburg
Prof. Dr. Dr. med. habil. Dr. phil. Dr. theol. h.c. Eckhard Nagel Institut für Medizinmanagement und Gesundheitswissenschaften Universität Bayreuth

Prieserstraße 2, 95444 Bayreuth, Germany eckhard.nagel@uni-bayreuth.de 


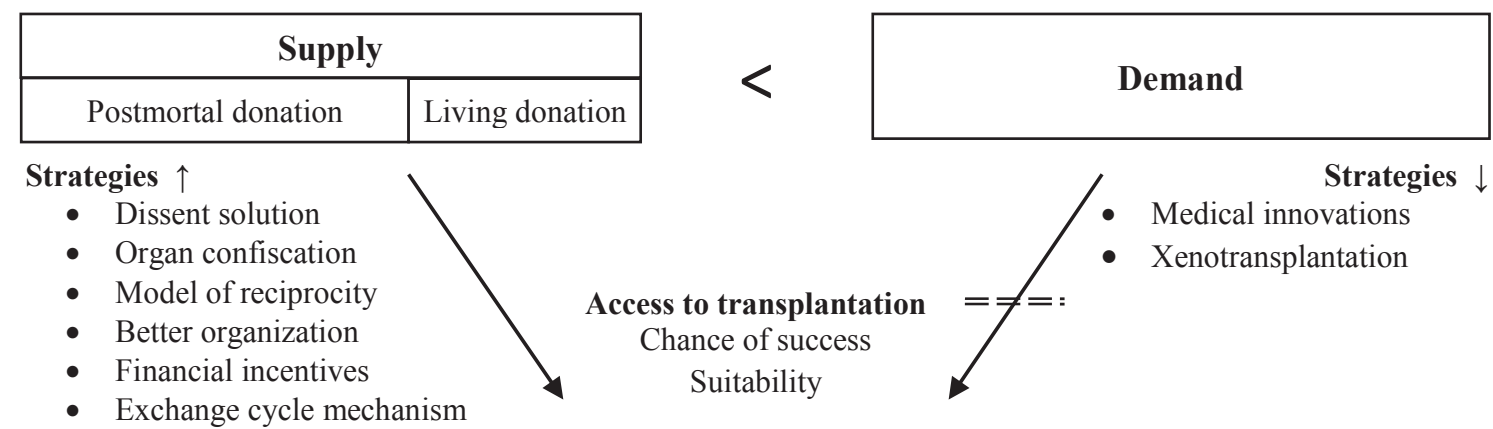

Fig. 1. Ethical issues in the face of organ scarcity

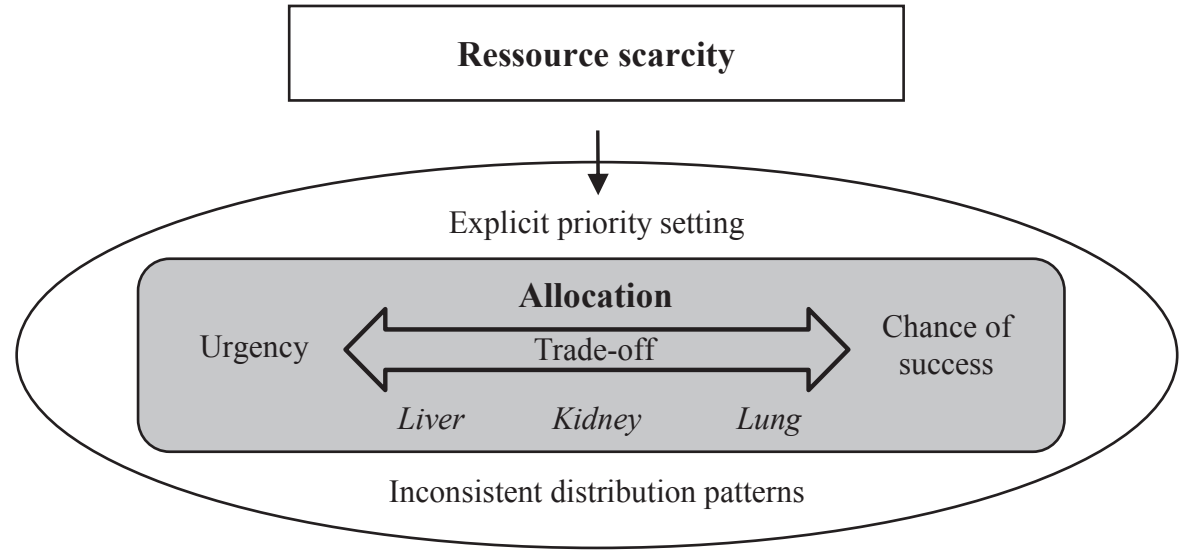

Table 1. Major ethical aspects

\begin{tabular}{ll}
\hline Principle & Strategies \\
\hline Respect for autonomy & $\begin{array}{l}\text { dissent solution } \rightarrow \text { donor/public: invasion of privacy } \\
\text { organ confiscation } \rightarrow \text { donor/public: withdrawal of the } \\
\text { decision-making power } \\
\text { financial incentives } \rightarrow \text { donor: social and economic } \\
\text { pressure }\end{array}$ \\
exchange cycle $\rightarrow$ donor: expansion of living donation \\
Non-maleficence & $\begin{array}{l}\text { xenotransplantation } \\
\text { Beneficence }\end{array}$ \\
& $\rightarrow$ recipient: unknown outcome \\
Justice & reciprocity $\rightarrow$ donor/recipient/public: justification of \\
& the exclusion from organ donation
\end{tabular}

Law), guidelines of self-regulatory bodies (particularly regulations of the German Medical Association), administrative data (e.g. from Eurotransplant), and professional discussions (e.g. literature from medical, normative, and empiric disciplines). This paper addresses the above-mentioned ethical issues descriptively with a focus on Germany and liver transplantation.

\section{Obtaining Consent in Times of Donor Shortage}

Different societies handle the question of obtaining consent for post-mortem organ donation in different ways. Three basic models are relevant to the understanding of the development of the current regulations in Germany. These models deal in substantially different ways with the trade-off between beneficence by increasing the number of available organ donors and the duty to respect au- tonomy and privacy [2-4]: i) The 'consent solution' implies an obligation to active agreement as a prerequisite for organ removal. In a narrower sense, a donor must agree during his/her lifetime while the next of kin are not authorized to decide on his/her behalf. Variations additionally require the absence of objection from or the active agreement of a next of kin named by the deceased person. An extended consent solution allows organ removal in the absence of a donor's documented consent if his/her next of kin give consent based on the deceased person's presumed will. ii) According to the 'dissent solution', an individual not willing to become an organ donor must actively reject donation. Thus, this model initially assumes an implicit consent to donation. An extension of this solution delegates the right of objection (e.g. in Belgium) to the next of kin. Valid documentation of the objection can be achieved through an Opting-Out Registry (as called in Austria) by written explanation or oral refusal witnessed by relatives. iii) The 'mandated choice solution' enforces public information and confrontation with the issue of organ donation. It imposes an individual decision, and guaranties its documentation.

In Germany, the Transplantation Act, or TPG, forms the legal basis for obtaining consent (in particular $\$ \$ 3,4$ (' $\$$ ' is used for section): Organ removal is legitimized by the donor's personal decision documented via an 'Organ Donor Card'. If a deceased person did not document a decision, organ removal requires consent by the next of kin considering the presumed will of their late relative. Moreover, it is possible to delegate the decision a priori by naming an authorized person during one's lifetime. This complex form of obtaining consent may be comprehensible in the light of the tradeoff between beneficence by increasing the number of donor organs 
and the respect for personal freedom. However, it has led to an empirically evident lack of documentation [5]: While the majority of Germans were willing to donate after death $(70 \%, 2012)$, only a minority documented their decision $(22 \%, 2012)$. Most of the Germans who documented their decision, gave consent to donate $(88 \%, 2012)$. Obviously, filling this gap could counteract the donor scarcity, and legislative change should provide countermeasures. Instead of the more restrictive approach to permit organ removal except for the case of active dissent, the German legislator decided in favor of the so-called 'decision solution'. The amendment came into effect at the end of 2012. Health insurers must and federal agencies (e.g. the Federal Center for Health Education) should inform the population about organ donation and request the declaration of a personal decision ( $\$ 2$ TPG). However, there is no obligation to document a decision, in other words no mandated choice. This might be the reason for the persistence of the documentation problem [6]. While the share of the population that holds an Organ Donor Card is constantly increasing, it is still not sufficient (35\%, 2014). Moreover, less than half of the population informs relatives and/or friends about their willingness to donate $(46 \%, 2014)$. This means that the next of kin have to decide without knowing the preferences of the potential organ 'source' (donor in this case seems to be the wrong word). This applied to 227 out of 773 cases with a positive decision and to 91 out of 370 cases in which relatives rejected organ removal in 2014 [7]. A second consequence of the unsolved documentation problem is that patients who could be saved are dying: International comparisons show that more incisive solutions lead to higher donor rates [3].

In sum, the base principle of beneficence justifies a shift from requests to voluntarily complete a donor card towards an obligation to document a decision. This shift is an acceptable invasion of privacy and can be enforced while continuing to respect autonomy. Independently of the specific approach, an obligation requires the provision of adequate medical educational material facilitating informed consent. This prerequisite is not fulfilled: In 2014, less than half the German population regarded themselves as well informed about organ donation [6].

\section{Prioritization: Allocation of Scarce Organs and Justice}

Modern transplantation medicine's most significant obstacle is the shortage of donors. Scarcity leads to inevitable allocation decisions. Obviously, somebody has to decide who should receive a post-mortem donor organ. This makes organ transplantation one of very few medical contexts in which explicit priority setting [8] is well established in Germany. The Transplantation Act prescribes fundamental material allocation principles: Organs must be distributed in particular according to 'prospect of success' and 'urgency' to suitable patients ( $\$ 12$ subsection 3 sentence 1 TPG). The expression 'in particular' could mean that additional principles are permitted - which is true for the criteria of equal opportunity derived from Basic Law [9]. Still more important is that the relationship between the guiding criteria, prospect of success and urgency, remains open. This is essential because prospect of success regularly decreases when transplantations become more urgent. The following example illustrates this general trade-off with regard to liver allocation: the Model for End-Stage Liver Disease (MELD) score (used as criterion for urgency) is not only a precise predictor of mortality on the waiting list [10], a high MELD score also is a patient-related risk factor indicating lower chances of success or survival rates after transplantation $[11,12]$. Patients with a higher MELD score need a donor organ more urgently but have worse prospects for a successful outcome [13].

Instead of addressing the operationalization of prospect of success and urgency as well as the weighting of these conflicting principles, the legislator delegates decisions to the German Medical Association ( $\$ 16$ subsection 1 sentence 1 number 5 TPG): This selfregulatory body issues directives for liver, kidney, heart, lung, pancreas, and small intestine allocation. This delegation faces legal objections against the involvement of non-state actors, e.g. regarding the lack of state control and transparency as well as unconstitutionality, which also applies to the role of Eurotransplant [9].

Another issue concerning the allocation directives exists independently of the lack of the German Medical Association's legitimization. Organ-specific directives differ with respect to the tradeoff between the guiding principles: The allocation of livers according to the MELD score follows the 'sickest-first' principle as it is primarily urgency-based [14]. In contrast, the lung allocation directive follows a utilitarian approach based on the lung allocation score (LAS), which expresses the benefit of transplantation as a function of life expectancy with and without transplantation (within several patient groups) [15]. In between, the rules for kidney allocation weigh up urgency-based criteria (e.g. waiting time) as well as success-based criteria (e.g. HLA matching) [16]. Differences in organ-specific allocation criteria are only in part based on medical reasons (e.g. availability of temporary treatment alternatives like dialysis). The diversity of how success and urgency are rated also becomes obvious when looking at the history of liver allocation: Prior to the adoption of the MELD score in 2006, waiting time was more important. However, while allocation based on the MELD score led to a decline in mortality on the waiting list, mortality and morbidity after transplantation got worse $[17,18]$.

Basically, there is no general agreement on whether to prioritize the sickest patient or to maximize the overall health benefit. This leads to unequal distribution patterns within transplantation medicine. Such vital decisions are obviously tangent to fundamental values and concepts of justice.

\section{Access to Transplantation: Controversial Discussions}

Transplantation centers are obliged to decide on whether to include or exclude patients from the waiting lists. With regard to $\$ 10$ subsection 2 number 2 TPG, the decision must be based on necessity and chance of success. Comparably to the allocation rules, the legislator delegates specification to the federal association of the 
German Medical Association ( $\$ 16$ subsection 1 sentence 1 number 2 TPG). The corresponding regulations determine general contraindications (see below) as well as organ-specific restrictions (see below). Both are viewed controversially. This also applies to another restriction of access to transplantation - the Milan criteria for hepatocellular carcinoma (see below).

Elementary legal reservations apply to each of these regulations: They refer to an illegitimate anticipation of allocation decisions since the requirements for expected success are set too high. The regulations exclude patients from the allocation process and do not weigh up different prospects of success. Hence, the justifying reasons for unequal treatment and the degree of inequality are not appropriately balanced. This conflicts with the strict legal requirements for just inequality due to personal characteristics. Moreover, the right of access and the right of total capacity utilization (derived from paragraph 2 sentence 1 of article 2 in conjunction with paragraph 1 of article 1 and paragraph 1 of article 3 Basic Law) are violated. Even if organs were not scarce, aiming for long-term success would exclude patients potentially benefitting from transplantation [19].

\section{Critical Analysis of General Contraindications}

The German Medical Association states that general contraindications 'can arise from findings, diseases, or circumstances, which significantly increase the risk of surgery or call the long-term success of transplantation into doubt'. Examples are i) not curatively treated malignant diseases which are not the reason for transplantation, ii) infectious diseases which are clinically manifest or negatively affected by immunosuppression, iii) serious diseases of other organs, and iv) severe medical-technical problems concerning the transplantation. The regulations describe another contraindication: 'A persistent lack of compliance precludes transplantation'. Even insufficient compliance can lead to a refusal of waiting list access on the grounds of contraindication [14].

These contraindications are subject to normative discussions: Requirements regarding the prediction of the recipient's survival time and the duration of graft function as well as the sustained improvement of quality of life must not be set too high at the level of the medical indication [20]. The minimum requirement for determining a lack of suitability is a medical prognosis indicating that the patient cannot be transplanted with a high probability [9]: Diseases listed as potential contraindications can only lead to refusal of waiting list access if they make it unlikely for a patient to be able for transplantation. In the same line, waiting list access can only be refused on the basis of non-compliance if a high risk of failure is predictable $[9,21]$. In contrast, regulations allegedly deviate from the conviction that medical prognosis must refer only to the individual suitability for transplantation and that a patient must not be compared to others [9]: Regulations do not consider whether a patient is suitable for transplantation as such, but rather whether one patient is more or less suitable compared to others. If unlikely long-term success leads to contraindication, access decisions according to current regulations are made by weighing up different patients' prospects of success.
Concluding, it is essential to determine whether a predicted absence of long-term success and insufficient compliance are always contraindications in the proper sense. Pure medical contraindications refer to measures which would do more harm than good or which are not practical (e.g. the shortening of life caused by transplantation or technical inoperability). Deviating from this concept may result in situations where transplantation is medically justified while regulations refuse access to the allocation process. In practice, contraindications in accordance with the regulations of the German Medical Association can differ from pure contraindications which do not consider donor shortage [22].

\section{Critical Analysis of Specific Restrictions for Liver \\ Transplantation}

Specific restrictions pertaining to waiting list access for liver transplantation demand that: i) there is no extrahepatic tumor growth in the case of malignant diseases (transplantation in advanced disease stages should only be done in controlled studies), ii) the defect (predictably) leads to irreversible damage in the case of metabolic/genetic diseases, iii) a disease-specific prognostic criterion indicates the need for transplantation in the case of acute liver failure, and iv) 6 months of total alcohol abstinence in the case of alcohol-induced liver cirrhosis must be completed [14]. In particular the latter point is the subject of controversial discussions. Arguments for refusing transplantation for alcohol-induced diseases relate to the alleged self-infliction as well as to concerns about posttransplant alcohol consumption resulting in a waste of grafts [23, 24]. The latter argument referring to the prospect of success is the basis for demanding 6 months of total alcohol abstinence in Germany. Even the medical literature has critically debated this rule for years: Weinrieb et al. [25] reviewed the literature on the 6-month rule's capability to forecast drinking behavior and its effect on the health consequences of alcohol consumption pre- and post-transplantation more than 15 years ago: They deduced that 'there is insufficient evidence to conclude whether there is a need for 6 months of stable pretransplantation abstinence in alcoholic liver transplant patients as a sole criterion to prevent complications associated with the transplantation surgery or recovery period'. The authors also remarked that drinking behavior is not foreseeable on the basis of 6 months of abstinence. Further, Weinrieb et al. [25] showed that in 6 of 9 controlled studies more non-alcoholics than alcoholics drank after transplantation. Beresford and Everson [26] also criticized the insufficient basis for the 6-month rule: 'Clinical prognosis is judged from a complex combination of observable phenomena, not an arbitrary 6-month rule that is indefensible but used by transplant programs because of its simplicity and its assuaging properties regarding transplant propriety'. The jury of a French consensus conference on medical indications for liver transplantation recommended in 2005 that patients with acute serious complications not responding to corticosteroids should have access to transplantation quicker [27]. The following analysis was the basis for this recommendation: Within a sample of 269 patients suffering from severe alcoholic hepatitis and medicated with corticosteroids, basic biological testing (lack of improvement of bilirubinemia at day 7) was able to 
forecast $80 \%$ of deaths along with a mortality of approximately 60 , 40 , and $25 \%$ at 1, 2, and 6 months, respectively, in the subgroup of non-responders. In recent years, Marthurin et al. [28] showed that early transplantation fundamentally improves the chances of survival of patients with severe alcoholic hepatitis not responding to medication. In this study, transplantation proceeded without adherence to the 6-month rule, which led to forceful discussions [23]. With reference to Marthurin et al. [28], and considering that a certain group of patients has only a very small chance of surviving 6 months, the rule was called into question [24]. However, although further limitations of the rule have been disclosed, such as the arbitrary determination of 6 months and the lack of predictive accuracy, it still seems to be accepted [23].

However, the 6-month rule is supported by certain medical evidence. It has been demonstrated that a shorter period of abstinence predicts problematic alcohol consumption after transplantation [29]. This evidence should be combined with old and new results suggesting to deviate from this rule. It is questionable whether a patient who has not been abstinent for 6 months is generally unsuitable for transplantation. Against this background, committing to 6 months might be practical but not indisputable.

\section{Critical Analysis of Restrictions for Hepatocellular Carcinoma}

The MELD score calculated based on laboratory parameters does not adequately indicate the urgency of a liver transplantation for all diseases. In these cases, transplantation centers can apply a matchMELD which in terms of urgency and prospect of success complies with the MELD score as it would be calculated for patients with other liver diseases. For patients suffering from hepatocellular carcinoma, this option is restricted amongst others by the Milan criteria determining the upper limit of the tumor size: Criteria are met if 1 tumor does not exceed $5 \mathrm{~cm}$ or 2-3 lesions do not exceed $3 \mathrm{~cm}$ [14].

The German Medical Association states that patients are not suitable for transplantation when these limits are exceeded because of an unfavorable prognosis [14]. In contrast, (legal) contributions criticize this rule emphasizing that patients who do not meet the criteria are excluded although they would significantly benefit from transplantation and that this might be unconstitutional [19]. Also, medical analyses give reason to weigh up the arguments: The 5 -year probability of survival of patients who meet the Milan criteria exceeds $70 \%$ [30]. 'However, for patients with disease beyond standard listing criteria, if progression of disease has not been extensive and there is no macroscopic vascular invasion or extrahepatic spread, the survival is comparable to patients transplanted for disease within the standard listing criteria. Most groups describe a 5 -year survival of around 50\% in patients transplanted for extended criteria' [30]. Nevertheless, the gatekeeping function potentially excludes patients only slightly exceeding the criteria. Hence, the attempt to select tumor patients who benefit from a transplant more than others is a result of scarcity [30,31]. 'Because these patients are deprived of liver transplantation ultimately because of the organ shortage and thus for selection reasons, living donor liver transplants might be a viable option' [31].
Against this background, loosening of the criteria is the subject of professional debate [32-34]. However, the German Medical Association adheres to the Milan criteria in their latest modification of the regulations in 2015 [14].

\section{Strategies to Prevent Organ Scarcity}

In the context of organ shortage, there are different strategies which can be pursued. On the one hand, certain strategies are associated with an increase in the supply of post-mortem organs, e.g. by increasing the willingness to donate. On the other hand, some strategies aim to reduce the demand, e.g. via the development of new treatment choices.

As mentioned above, there are different legal regulations with regard to whether the population has to consent or explicitly dissent to post-mortem organ donation. These concepts finally affect the quantity of organs available [3]. The dissent solution (e.g. in Austria) assumes that all inhabitants of a population are potential organ recipients and thereby justifies all inhabitants being seen as potential donors [35]. When comparing the number of deceased donors per million population per year, in Austria this number was more than twice as high (24.3) as in Germany (10.5) in 2014 [1]. Although the number of potential donors is influenced by many other factors like social or cultural aspects, the difference between Austria and Germany can be explained by the fact that the Austrian legislator deliberately decided that the protection of a deceased person is not more important than the protection of life [3]. The confiscation of post-mortem organs implies that all inhabitants of a country are potential organ donors. This concept is based on the idea of solidarity and the collective right to access post-mortem organs as any member of a solidly united society could also be a potential recipient [35]. Even if a person refuses post-mortem donation, organ removal is still possible [36]. Thus, the confiscation of post-mortem organs establishes an obligation towards society in which the community's interest is more relevant than the autonomy of a deceased person [37]. Furthermore, there is a model of reciprocity, also known as 'club solution', 'model of solidarity', or 'organ pool': The willingness to donate organs is a prerequisite for gaining the right to receive an organ [35]. There are various forms of how this model can be implemented into an existing system: Firstly, the willingness/unwillingness to donate can lead to a bonus/malus on the waiting list [35]. A restrictive interpretation of this regulation implies either an exclusion from or an inclusion on the waiting lists depending on the person's willingness [37]. Secondly, there is the option of founding an insurance company under private law. The insured persons consent to post-mortem donation under the condition that only members of the insurance company get the removed organ [35]. Thirdly, the population can choose if organs are to be donated to all other citizens or only to those who are also willing to donate. This could be documented on an Organ Donor Card for instance. Generally, one disadvantage of various 'small' pools is that tissue must be compatible for transplantation. Hence, the pool of potential donors should be as large as possible 
[35]. With regard to legal provisions, the organization and professionalization of donation plays a key role in the strategic increase in the number of donors. Spain as the country with the highest number of organ donors (35.9 per 1 million people per year [38]) is an exemplary model. Whereas other European countries usually focus on the distribution of organs, Spain concentrates on the donation. In this context, the ONT (Organización National de Trasplantes) as a public institution of the Spanish Ministry of Health plays an important role. The ONT determines measures on an economic, medical, ethical, and legal basis which comprise e.g. transplant coordinators. Professionalization includes the medical and intensive medical expertise of the coordinators, and specific training for doctors in intensive care units and emergency departments. As a consequence, they are responsible for the identification of possible organ donors in the hospitals and can sensitize physicians to potential organ donation. Although there is the dissent solution and everyone who does not actively refuse organ donation is a potential donor in Spain, the coordinators conduct an interview with the next of kin and let them decide whether or not their brain-dead relative should become an organ donor. The trained doctors and coordinators integrate special approaches into their conversation techniques to persuade relatives to consent to donation [39]. In addition, financial incentives can strategically increase the organ supply. In relation to selling organs, the price would be based on the current supply and demand. It is expected that organ scarcity could be reduced by increasing the willingness to donate with financial incentives, but this stimulus will not be sufficient to prevent organ shortage. Ethic concerns emphasize that donors are influenced by external or economic constraints [40]. This applies to post-mortem as well as living donation. Further, a dependency between donor and recipient could arise from organ trafficking. It is speculative whether a person with low financial resources would prefer to sell his/her organs in order to earn money. Especially low income countries could be affected by the development of a black market. Also, due to medical infrastructure deficits, there is a high health risk. In accordance with TPG, organ trafficking is not permitted in Germany; especially the remuneration of organ donors is prohibited ( $\$ 17$ subsection 1 sentence 1 ) [41].

Among the strategies concerning the increase of supply there are some approaches focusing on the reduction of demand. Chronic hepatitis $\mathrm{C}$ infection which leads to liver failure is the most frequent cause of liver transplantation. After transplantation, many patients suffer a hepatitis $C$ relapse and are put on the waiting list for a second time. In recent times, patients have been profiting from improved medical treatments associated with a lower rate of severe adverse events as well as a high rate of sustained virological response (SVR) [42]. Since their approval in 2011, the new protease inhibitors boceprevir and telaprevir have led to significantly improved SVR rates. Bocaprevir and telaprevir were typically prescribed in combination with interferon and resulted in various side effects. In 2014, further antiviral substances were successfully brought to the market. These second-generation substances do not need to be combined with interferon while being associated with shorter treatment time and higher efficacy [43]. It is expected that innovative treatments such as for hepatitis $\mathrm{C}$ have an impact on the waiting lists and thereby on the scarcity of organs. Furthermore, xenotransplantation offers the prospect of replacing a human organ with that of an animal. First attempts included the unsuccessful transplantation of a pig's liver into a baboon, and the first chimpanzee's liver was transplanted into a human in 1966 . So far, all attempts have been unsuccessful. Due to the complexity of the metabolic processes in the liver, it is expected that this organ is one of the last to ever be xenogeneically transplanted. However, in the case of successful development, xenotransplants could replace allotransplants if they had a comparable outcome from the patient's point of view. Further, xenotransplants could be used to bridge the waiting time until a compatible allotransplant becomes available. This could positively affect the situation regarding organ scarcity and waiting lists [44]. Another model to improve the matching of living kidney donation originated from Alvin Roth and Lloyd Shapley [45, 46]. Due to the fact that genetic characteristics and tissue type (HLA type) influence the success of kidney transplantation, an exchange cycle mechanism based on game theory is suggested: To avoid that a kidney of a healthy person is incompatible with the intended recipient, a cyclic exchange between the incompatible pairs is proposed. This system is used for example in New England since 2001. Any person who needs a kidney and has an incompatible donor is able to register with the Alliance for Paired Donation. Monthly match runs can identify potentially compatible pairs. Matching is theoretically not limited to 1 matched pair as 3 or more recipient pairs may be identified (so-called 'domino transplants' or 'chains'). This system aims at improving patient outcome (for an exemplary approach see www.kidneylink.org).

Based on the four principles of biomedical ethics according to Beauchamp and Childress [47] - respect for autonomy, non-maleficence, beneficence, and justice - the strategies conducive to closing the gap between the high number of needed and the low number of donated organs are critically reviewed, and the main problems from an ethical point of view are stated in the following (table 1).

Various strategies are in conflict with the respect for autonomy. The dissent solution infringes the autonomy of potential organ donors by invasion of privacy as it is based on the assumption that any person is an organ donor unless donation is actively refused. Organ confiscation is even more restrictive as it is accompanied by the withdrawal of the decision-making power. This strategy disregards the freedom of decision because the societal beneficence of saving as many people as possible is seen as being of higher value than the autonomy of an individual. With financial incentivization, autonomy is also violated since the potential donors may be under social and economic pressure which could result in a forced donation.

The exchange cycle concept on the other hand raises questions regarding non-maleficence. This concept aims at maximizing the compatibility of living kidney donations. In Germany, in accordance with TPG, living donations (far-reaching interventions in a healthy person) are only permitted if a post-mortem organ is not available at the time of organ removal ( $\$ 8 \mathrm{TPG})$.

With regard to the principle of beneficence, especially xenotransplantation should be viewed critically with particular reference to un- 
known patient outcomes and various other risks. As xenotransplantation is currently not an established method, the utility of this form of transplantation is unknown. The wellbeing of the patient could further be impaired by zoonotic diseases since the transmission of viral infections in transplants is not yet completely understood.

Lastly, the model of reciprocity especially relates to matters of justice: An interpretation of the equity principle might justify the consideration of whether or not a patient who needs a transplantation is also willing to donate. This point of view might even justify refusal of access. However, an orientation towards a principle of need would grant access independently of reciprocity considerations.

\section{Discussion}

Various strategies can reduce the demand or increase the supply of donor organs. Due to a lack of consensus or a lack of medicaltechnical feasibility, most strategies cannot be readily adapted. We propose to focus on recent most promising strategies to counteract scarcity in the short-term: i) Demanding a documented decision is justified by the basic principle of beneficence and is an acceptable invasion of privacy. Especially in the context of the unsolved documentation problem in Germany, this strategy seems to offer great potential. Based on international experiences (e.g. Austria) and practical aspects, a dissent solution is an adequate approach. This would also reflect the German society's basically positive attitude towards organ donation. Any request for a decision must respect the autonomy of the individual by ensuring that all concerned are able to express their will. This includes both facilitating informed consent by adequate and differentiated medical education as well as providing information about specific legal regulations and their consequences. ii) An orientation towards the Spanish model implies improved organization and professionalization of processes. The adaption of certain components like the comprehensive dissemination of specialized transplantation coordinators would increase the number of available organs. However, no combination of these strategies will entirely overcome scarcity in the mid-term. Tragic decisions regarding organ allocation will remain inevitable. These decisions must be made within the actual allocation process. Taking this into account, restrictions of access to liver transplantation are criticized not only from a legal perspective. Concepts like the 6-month rule must constantly be reviewed considering all medical evidence. This might lead to a more comprehensive differentiation. In any case, specific access regulations must not be based on moralism but rather on consistent and impartial assessment. Some restrictions potentially apply unjustifiably high standards regarding the prospect of success. As an alternative, certain aspects of success could be integrated in the allocation process on the basis of the MELD score. Concepts like the D-MELD [12] and the SOFT score [48] can be taken into consideration. These particularly help to avoid risky donor-recipient combinations and depict mortality after liver transplantation. Beyond liver transplantation, we should examine all current allocation rules with regard to the different weighting of allocation principles which leads to unequal distribu- tion patterns: Due to the conflict between prioritizing the sickest first based on the principle of urgency and maximizing the overall health benefit based on the principle of success, allocation decisions become value judgments. These judgments go beyond the responsibility of the medical profession. Ultimately, prioritization in transplantation medicine is a matter of distributing life chances. There is a wide consensus that normative disciplines (jurisprudence and ethics) can give important advice. Moreover, it is often suggested to consider public preference (beyond the elements of representative democracy) $[49,50]$ : As decisions on organ allocation directly affect citizens, public preferences must be considered with regard to autonomy. Moreover, the members of a solidly united society finance the healthcare system (of which transplantation medicine is a part). Given the lack of legitimacy and democracy assumed for several health systems, public participation or consultation seem advisable. Furthermore, it is discussed that decisions considering public preferences in the decision-making process are of better quality as they reflect social values and citizens' expectations. This leads to higher acceptance and strengthens the confidence in the (transplantation) system. However, there are only a few studies analyzing public preferences regarding organ allocation in Germany: Gross und Kriwy [51] conducted a factorial survey among graduate students who were challenged to prioritize organ recipients within a fictive group of patients. Umgelter et al. [52] conducted a questionnaire survey among patients and medical staff focusing on the distribution of organs according to urgency and outcome maximization in liver transplantation. Further, a pilot study at the University of Bayreuth successfully analyzed within a Discrete Choice experiment the balance of urgency and chance of success without referring to a specific organ type [53]. The continuation of this study promises to fill the gap left by empirical evidence. Another example highlights the importance of the public in transplantation medicine: In July 2012, it was made public that German physicians manipulated laboratory test results in order to reduce their patients' waiting time. This immediately resulted in a reduction in the number of organ donations, which can be attributed to loss of confidence. In 2014, the results of a survey by the Federal Centre for Health Education concerning attitude and behavior with regard to organ donation [6] showed that $50 \%$ of the German population had lost confidence in the system. As a consequence, not the physicians who had manipulated the test results but the patients suffered due to a decrease in organ donations [54]. However, the main reasons for refusal to donate organs are the ancient fears of abuse and organ trafficking and unfair allocation of organs as well as indecisiveness. In sum, external surveillance is needed in order to strengthen confidence. Transparency should aid the general public's understanding of allocation criteria such as 'chance of success' and 'urgency', as well as the quality and safety of organ donation [55].

\section{Disclosure Statement}

No conflict of interest. 


\section{References}

1 Eurotransplant International Foundation: Annual Report 2014. Leiden, Eurotransplant International Foundation, 2015.

2 Holznienkemper T: Organspende und Transplantation und ihre Rezension in der Ethik der abrahamitischen Religionen. Münster, LIT, 2005.

3 Bruckmüller K, Schroth U: Power of legal concepts to increase organ quantity; in Jox JR, Assadi G, Marckmann G (eds): Organ Transplantation in Times of Donor Shortage: Challenges and Solutions. Cham, Springer International Publishing, 2016, pp 167-177.

4 Deutscher Ethikrat: Nutzen und Kosten im Gesundheitswesen - Zur normativen Funktion ihrer Bewertung. Berlin, Deutscher Ethikrat, 2011

5 Watzke D, Schmidt K, Stander V: Einstellung, Wissen und Verhalten der Allgemeinbevölkerung zur Organ und Gewebespende: Zusammenfassung der wichtigsten Ergebnisse. Köln, Bundeszentrale für gesundheitliche Aufklärung, 2013.

6 Caille-Brillet A-L, Schmidt K, Watzke D, Stander V: Bericht zur 2014 Repräsentativstudie «Wissen, Einstellung und Verhalten der Allgemeinbevölkerung zur Organ- und Gewebespende». Köln, Bundeszentrale für Gesundheitliche Aufklärung, 2015.

7 Deutsche Stiftung Organtransplantation: Jahresbericht 2014. Frankfurt am Main, 2015.

8 Nagel E, Lauerer M (eds): Prioritization in Medicine: An International Dialogue. Cham, Springer, 2016.

9 Bader M: Organmangel und Organverteilung. Tübingen, Mohr Siebeck, 2010.

10 Wiesner R, Edwards E, Freeman R, Harper A, Kim R, Kamath P, Kremers W, Lake J, Howard T, Merion RM, Wolfe RA, Krom R: Model for end-stage liver disease (MELD) and allocation of donor livers. Gastroenterology 2003;124:91-96.

11 Saab S, Wang V, Ibrahim AB, Durazo F, Han S, Farmer DG, Yersiz H, Morrisey M, Goldstein LI, Ghobrial RM, Busuttil RW: MELD score predicts 1-year patient survival post-orthotopic liver transplantation. Liver Transpl 2003;9:473-476

12 Halldorson JB, Bakthavatsalam R, Fix O, Reyes JD, Perkins JD: D-MELD, a simple predictor of post liver transplant mortality for optimization of donor/recipient matching. Am J Transplant 2009;9:318-326.

13 Habib S, Berk B, Chang CC, Demetris AJ, Fontes P, Dvorchik I, Eghtesad B, Marcos A, Shakil AO: MELD and prediction of post-liver transplantation survival. Liver Transpl 2006;12:440-447.

14 Bundesärztekammer: Richtlinien zur Lebertransplantation. Berlin, Bundesärztekammer, 2015.

15 Bundesärztekammer: Richtlinien zur Lungentransplantation. Berlin, Bundesärztekammer, 2013.

16 Bundesärztekammer: Richtlinien zur Nierentransplantation. Berlin, Bundesärztekammer, 2013.

17 Bobbert M, Ganten TM: Liver allocation: urgency of need or prospect of success? Ethical considerations. Clin Transplant 2013;25:34-39.

18 Weismuller TJ, Fikatas P, Schmidt J, Barreiros AP, Otto G, Beckebaum S, Paul A, Scherer MN, Schmidt HH, Schlitt HJ, Neuhaus P, Klempnauer J, Pratschke J, Manns MP, Strassburg CP: Multicentric evaluation of model for end-stage liver disease-based allocation and survival after liver transplantation in Germany - limitations of the 'sickest first'-concept. Transpl Int 2011; 24:91-99.

19 Dannecker G, Streng AF, Ganten TM: Zur Reformbedürftigkeit des gegenwärtigen Allokationsmodus für postmortal gespendete Lebern - Vom «Sickest First»-Prinzip zum «Most Lives Saved»-Ansatz; in Schmitz-Luhn B, Bohmeier A (eds): Priorisierung in der Medizin: Kriterien im Dialog. Berlin, Springer, 2013, pp 147-160.
20 Schroth U, Gutmann T, König P: Transplantationsgesetz: Kommentar. München, Beck, 2005.

21 Lachmann RM, Meuter N: Medizinische Gerechtigkeit: Patientenauswahl in der Transplantationsmedizin. München, Wilhelm Fink, 1997.

22 Lauerer M, Baier C, Alber K, Nagel E: Berücksichtigung der Erfolgsaussicht bei der Allokation von Spenderlebern; in Schmitz-Luhn B, Bohmeier A (eds): Priorisierung in der Medizin: Kriterien im Dialog. Berlin, Springer, 2013, pp 161-174

23 Donckier V, Lucidi V, Gustot T, Moreno C: Ethical considerations regarding early liver transplantation in patients with severe alcoholic hepatitis not responding to medical therapy. J Hepatol 2014;60:866-871.

24 Brown RS Jr: Transplantation for alcoholic hepatitis time to rethink the 6-month 'rule'. N Engl J Med 2011; 365:1836-1838.

25 Weinrieb RM, Van Horn DH, McLellan AT, Lucey MR: Interpreting the significance of drinking by alcohol-dependent liver transplant patients: fostering can dor is the key to recovery. Liver Transpl 2000;6:769776.

26 Beresford TP, Everson GT: Liver transplantation for alcoholic liver disease: bias, beliefs, 6-month rule, and relapse - but where are the data? Liver Transpl 2000;6: $777-778$.

27 No authors listed: Consensus conference: indications for liver transplantation, January 19 and 20, 2005, Lyon-Palais Des Congres: text of recommendations (long version). Liver Transpl 2006;12:998-1011.

28 Mathurin P, Moreno C, Samuel D, et al: Early liver transplantation for severe alcoholic hepatitis. N Engl J Med 2011;365:1790-1800.

29 Tandon P, Goodman KJ, Ma MM, Wong WW, Mason AL, Meeberg G, Bergsten D, Carbonneau M, Bain VG: A shorter duration of pre-transplant abstinence predicts problem drinking after liver transplantation. Am J Gastroenterol 2009;104:1700-1706.

30 Bruix J, Sherman M: Management of hepatocellular carcinoma. Hepatology 2005;42:1208-1236.

31 Timm S: Aktuelle Aspekte bei der Lebertransplantation. Bayerisches Ärztebl 2006;7-8:335-357.

32 Yao FY, Ferrell L, Bass NM, Watson JJ, Bacchetti P, Venook A, Ascher NL, Roberts JP: Liver transplantation for hepatocellular carcinoma: expansion of the tumor size limits does not adversely impact survival. Hepatology 2001;33:1394-1403.

33 Roayaie S, Frischer JS, Emre SH, Fishbein TM, Sheiner PA, Sung M, Miller CM, Schwartz ME: Long-term results with multimodal adjuvant therapy and liver transplantation for the treatment of hepatocellular carcinomas larger than 5 centimeters. Ann Surg 2002;235: 533-539.

34 Marsh JW, Dvorchik I: Liver organ allocation for hepatocellular carcinoma: are we sure? Liver Transpl 2003; 9:693-696.

35 Breyer F, van den Daele W, Engelhard M, Gubernatis G, Kliemt H, Kopetzki C, Schlitt HJ, Taupitz J: Organmangel. Ist der Tod auf der Warteliste unvermeidbar? Berlin, Springer, 2006.

36 Pühler W, Middel CD, Hübner M: Praxisleitfaden Gewebegesetz. Grundlagen, Anforderungen, Kommentierungen. Köln, Deutscher Ärzte-Verlag, 2009.

37 Nationaler Ethikrat: Stellungnahme: Die Zahl der Organspender erhöhen - zu einem drängenden Problem der Transplantationsmedizin in Deutschland. Berlin, Druckhaus Berlin-Mitte, 2007.

38 The European Committee on Organ Transplantation: Newsletter Transplant: International Figures on Donation and Transplantation 2014. Strasbourg, European Directorate for the Quality of Medicines \& HealthCare of the Council of Europe, 2015.
39 Badcock J: How Spain Became the World Leader in Organ Donations. www.newsweek.com/2015/02/20/ spain-has-become-world-leader-organ-donations305841.html.

40 Nagel E, Alber K: Implikationen und Optionen des europäischen Rechts: Die ärztliche Perspektive; in Middel CD, Pühler W, Lilie H, Vilmar K (eds): Novellierungsbedarf des Transplantationsrechts: Bestandsaufnahme und Bewertung. München, Deutscher Ärzteverlag, 2010, pp 227-236.

41 Hebborn A: Möglichkeiten und Grenzen eines Marktes für Organtransplantate. Bayreuth, P.C.O., 1998.

42 Kwo PY, Mantry PS, Coakley E, Te HS, Vargas HE Brown RJ, Gordon F, Levitsky J, Terrault NA, Burton JRJ, Xie W, Setze C, Badri P, Pilot-Matias T, Vilchez RA, Forns X: An interferon-free antiviral regimen for HCV after liver transplantation. N Engl J Med 2014; 371:2375-2382.

43 Schneider MD, Kronenberger B, Zeuzem S, Sarrazin C: Treatment of hepatitis C. Internist 2015;56:391-405.

44 Beckmann JP, Brem G, Eigler FW, Günzburg W, Hammer C, Müller-Ruchholtz W, Neumann-Held EM, Schreiber HL: Xenotransplantation von Zellen, Geweben oder Organen: Wissenschaftliche Entwicklungen und ethisch-rechtliche Implikationen. Berlin, Springer, 2000.

45 Ashlagi I, Jaillet P, Manshadi VH, Rees MA: Kidney exchange in dynamic sparse heterogenous pools. arXiv preprint arXiv:1301.3509, 2013.

46 Roth AE, Sönmez T, Ünver MU: Kidney exchange. Quarterly J Econom 2004;119:457-488.

47 Beauchamp TL, Childress JF: Principles of Biomedical Ethics, ed 6. Oxford, Oxford University Press, 2008.

48 Rana A, Hardy MA, Halazun KJ, Woodland DC, Ratner LE, Samstein B, Guarrera JV, Brown RS Jr, Emond JC: Survival outcomes following liver transplantation (SOFT) score: a novel method to predict patient survival following liver transplantation. Am J Transplant 2008;8:2537-2546

49 Bruni RA, Laupacis A, Martin DK: Public engagement in setting priorities in health care. CMAJ 2008; 179:1518.

50 Williams I, Robinson S, Dickinson H: Rationing in Health Care: The Theory and Practice of Priority Setting. Bristol, Policy Press, 2011.

51 Gross C, Kriwy P: Einstellungen zu einer gerechten Organallokation: Ergebnisse einer Vignettenanalyse. Gesundheitswesen 2008;70:541-549.

52 Umgelter KS, Tobiasch M, Anetsberger A, Blobner M, Thorban S, Umgelter A: Donor organ distribution according to urgency of need or outcome maximization in liver transplantation. A questionnaire survey among patients and medical staff. Transpl Int 2015;28:448454.

53 Dao Van M, Lauerer M, Schätzlein V, Nagel E: Organallokation im Spannungsfeld zwischen Erfolgsaussicht und Dringlichkeit - ein Discrete Choice Experiment zur Erhebung von Präferenzen in der Bevölkerung. Gesundheitswesen 2016;paper accepted for publication.

54 Nagel E, Bayerl B, Lauerer M: Hoffnungsträger Organtransplantation; in Sterzik S (ed): Zweites Leben: Organe spenden - ja oder nein? Berlin, Wichern, 2013, pp 143-154.

55 Hess R: Sicherung der Transplantationsmedizin. Aufgaben der Deutschen Stiftung Organtransplantation. Medizinische Klinik - Intensivmedizin und Notfallmedizin 2014;109:403-407. 